\title{
Sensitivity of estuaries to sea level rise: Vulnerability indices
}

David Prandle ${ }^{a, b}$ and Andrew Lane ${ }^{a, *}$

${ }^{a}$ National Oceanography Centre, Joseph Proudman Building, 6 Brownlow Street, Liverpool L3 5DA United Kingdom

$b$ Department of Earth, Ocean and Ecological Sciences, University of Liverpool, 4 Brownlow Street, Liverpool L69 3 GP United Kingdom

* Corresponding author, e-mail: ale@noc.ac.uk

Keywords: estuarine dynamics; sea level changes; climatic change; shallow water tides; saline intrusion; UK, England and Wales

\section{Highlights}

- Vulnerability Indices gauge climate change impacts of varying sea level \& river flow

- Indices show effects on: mass flow, energetics, vertical mixing and saline intrusion

- UK estuaries - impact greatest in shallow estuaries, least in large/deep (>10 m) ones

- Scale of 'direct dynamical' impacts similar to earlier morphology evolution estimates

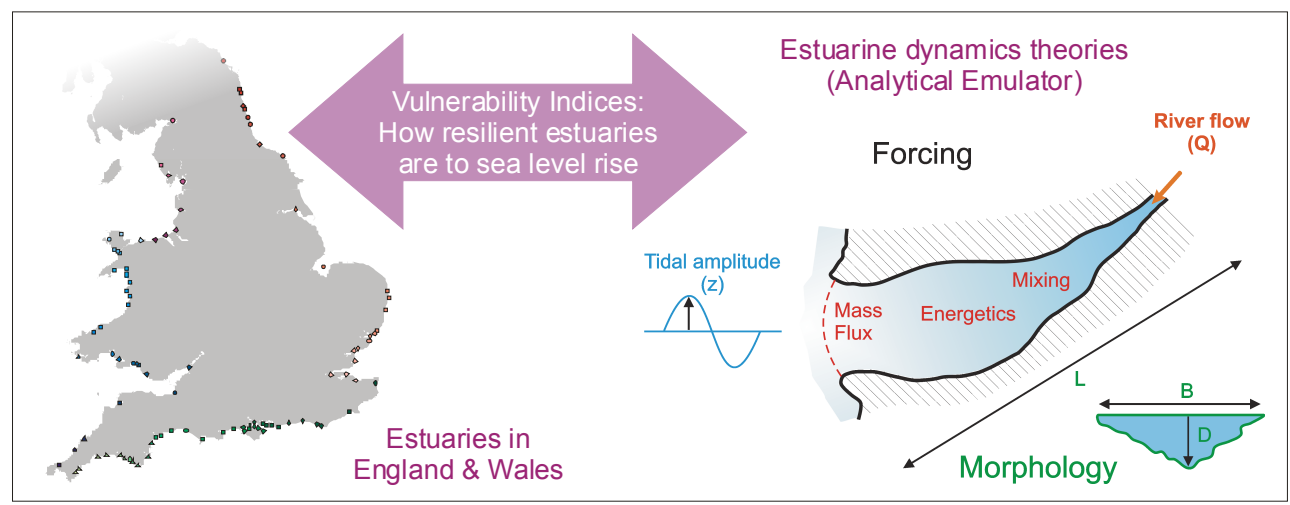

\section{Abstract}

This study addresses the question of how tidally-dominated estuaries will adapt to rises in mean sea level and changes in river flows associated with global climate change. The aim was to develop generic 'Vulnerability Indices' to provide immediate indications of relative resilience or sensitivity. Four indices indicate the likely impacts on: (1) Mass flow, (2) Energetics, (3) Vertical mixing and (4) Salinity intrusion.

Application of these indices to 96 estuaries in England and Wales suggests that a mean sea-level rise of $1 \mathrm{~m}$ will:

- have little overall effect on mass flows but significant impacts on energy dissipation levels, especially in depths less than about $10 \mathrm{~m}$ 
- have a small impact on levels of vertical mixing in deeper estuaries, but a significant impact in shallow $(<10 \mathrm{~m})$, micro-tidal estuaries

- increase the salinity intrusion length by at least $7 \%$ in the deepest estuaries and by in excess of $25 \%$ in estuaries shallower than $10 \mathrm{~m}$.

In seaward regions of strongly tidal estuaries, impacts from changes in river flow, $Q$, have little effect on either mass flow or energetics. However, a change of $25 \%$ (either increase or decrease) will have significant effects on both vertical mixing and salinity intrusion. The impacts on vertical mixing will be greatest in estuaries closer to micro-tidal conditions. Saline intrusion lengths will increase in proportion to the related decrease in river flow (and vice versa).

These impacts must be considered alongside likely accompanying evolution in morphologies indicated by Prandle (2006).

\section{Introduction}

The Intergovernmental Panel on Climate Change indicates a range of likely scenarios over the next century. While sea level has risen by $10-20 \mathrm{~cm}$ over the last century, rises forecast for the next century range between 9 and $90 \mathrm{~cm}$ (IPCC, 2001). Similarly, changes in rainfall, and thereby river flows, may be of the order of $25 \%$ over the UK. Its latest report (IPCC, 2014) refined the sea level rise as between 17 and $21 \mathrm{~cm}$ during 1901-2010 with a mean rate of 1.7-2.3 $\mathrm{mm} \mathrm{yr}^{-1}$ since 1971 .

It can be shown that, in 'Synchronous Estuaries' (where the sea surface slope due to the axial gradient in phase of tidal elevation significantly exceeds the gradient from changes in tidal amplitude: Dyer, 1997), bathymetries reflect the influences of tidal amplitude, $Z$, and river flow, $Q$, alongside some representation of the alluvium. Prandle (2006) showed how the bathymetries from 80 UK estuaries could be largely explained from these theoretically derived relationships. This success provided the basis for estimating how future bathymetries may adjust under the influences of changes in mean sea level and river flows associated with global climate change. Here, we extend these estimates to consider the impacts on tidal dynamics and saline intrusion and associated vertical mixing conditions.

Away from the upper reaches, in the meso- and macro-tidal estuaries found around the UK, river flow has little influence on tidal dynamics. Hence the major impact of global climate change on 
tidal dynamics in these estuaries is likely to be a change in mean sea level. However, changes in river flows impact more immediately on saline intrusion and associated stratification.

Section 2 outlines the theory of tidal response and associated morphological development.

Section 3 illustrates the range of 96 estuarine morphologies (extended version of original 80 estuaries in England and Wales) and their associated forcing parameters. The success in explaining existing morphologies (Prandle, 2006) in terms of the forcing parameters of tidal amplitude, $Z$, and river flow, $Q$, is summarised in Figs. 3 and 4. These data are used for determining the statistical nature of these links between morphologies and forcing, and thence for comparing with the corresponding theoretical derivations.

While individual estuaries exhibit localised features (related to underlying geology, flora and fauna, historical development and human intervention), the overall values of depth and length are shown (in Figs. 3 and 4, and Tables 2 and 3) to be consistent with the theories described in Section 2. In particular, the morphological features which characterise Rias, Coastal Plain and Bar-Built estuaries can be rationalised by reference to these theories.

In Section 4, four indices of vulnerability are derived, indicating the likely impacts of global climate change in tidally-dominated estuaries on: (1) Mass flow, (2) Energetics, (3) Vertical mixing and (4) Salinity intrusion. A summary of the extent of morphological impacts on UK estuaries is provided in Table 4.

Section 5 summarises the types of estuaries most at risk, greatest impacts will be seen for shallow estuaries, with the deepest estuaries exhibiting much greater resilience.

\section{Theory of tidal response and associated morphology}

\subsection{Constraints on application}

The complexity of estuaries means that it is necessary to make certain assumptions in order to be able to provide analytical solutions for the diverse range of dynamic interactions and mixing processes. The following assumptions are adopted for the theoretical solutions shown here: 
1) Consideration of a single tidal constituent - the principal lunar semi-diurnal tidal constituent, $\mathrm{M}_{2}$ - provides the basis for linearisation of dynamical equations.

2) Linearisation of the quadratic bed friction formulae is valid for the strongly tidal estuaries of the UK.

3) The coefficients of eddy viscosity and diffusivity are assumed to be vertically and temporally constant with magnitudes proportional to a product of the bed friction coefficient, tidal velocity amplitude and water depth. These approximations are generally valid in strongly tidal, shallow, well mixed estuaries.

4) The use of 'Synchronous Estuary' solutions.

Recent papers by van Rijn (2011), Brown and Davies (2007), and Wang et al. (2009) describe additional processes involved in estuarine dynamics and associated morphological evolution.

\subsection{Estuarine theories}

Theories for estuarine dynamics are cited here and used subsequently to link changes in external forcing conditions to impacts on these dynamics and associated morphologies. Fig. 1 indicates the processes and variables considered.

\subsubsection{Synchronous solutions}

By introducing the assumption of a synchronous estuary, where surface gradients generated by tidal phase change predominate over those via tidal amplitude variations, Prandle (2004a) derived explicit expressions for the amplitude, $U$, and phase, $\theta$, of tidal currents relative to elevation, alongside the tidal length, $L$, of an estuary in terms of the tidal elevation amplitude, $Z$, water depth, $D$, and bed friction coefficient, $f$.

$$
\begin{gathered}
\begin{array}{rl}
U=Z & g k /\left(\omega^{2}+F^{2}\right)^{1 / 2} \\
\tan \theta & =-F / \omega \\
& =S L /(0.5 D k)
\end{array} \\
k=\frac{\omega}{(0.5 D g)^{1 / 2}}
\end{gathered}
$$




$$
L=\frac{D_{0}^{5 / 4}}{Z^{1 / 2}} \frac{4}{5} \frac{(2 g)^{1 / 4}}{(1.33 f \omega)^{1 / 2}} \sim 2460 \frac{D_{0}^{5 / 4}}{Z^{1 / 2}} \quad \text { for } \quad f=0.0025
$$

with the linearised bed friction coefficient, $F=1.33 f U / D$. In Equations $1-4, g$ is the acceleration due to gravity, $\omega=2 \pi / P$ is the tidal frequency, $P$ is the tidal period, $S L$ is the axial bed slope, $k$ is the speed of the tidal phase propagation, and $D_{0}$ is the depth at the mouth of the estuary.

The adoption of this 'synchronous' assumption enables an analytical emulator to be formulated, incorporating tidal dynamics, saline intrusion, and sediment mechanics (Prandle, 2004b). This emulator provides explicit expressions for saline intrusion length, $L_{\mathrm{I}}$,

$$
L_{\mathrm{I}}=0.005 D_{0}^{2} /\left(f U U_{0}\right) .
$$

where $U_{0}$ is the river flow velocity and $D_{0}$ depth at the mouth. The emulator suggests that bathymetric stability is maintained via a combination of tidal dynamics and 'delayed' settlement of sediments in suspension and can be used to derive conditions necessary to maintain zero net flux of sediments, i.e., bathymetric stability.

By introducing the observation that mixing occurs at a minimum in landward intrusion of salt, an expression linking the depth at the mouth of an estuary, $D_{0}$, with river flow, $Q$, was derived (Prandle, 2004a and 2004b), thus:

$$
D_{0}=12.8(Q \tan \alpha)^{0.4}
$$

assuming a triangular cross section with side slopes, $\tan \alpha$.

This expression is independent of both tidal elevation amplitude, $Z$, and bed friction coefficient, $f$. Hence, the river flow velocity, $U_{0}$, within the saline intrusion zone, can be given in mixed estuaries by

$$
U_{0}=D_{0}^{0.5} / 333 \mathrm{~m} \mathrm{~s}^{-1}
$$

and is invariably of the order of $1 \mathrm{~cm} \mathrm{~s}^{-1}$ for $2<D_{0}<50 \mathrm{~m}$.

The above expressions for length, $L$, and depth at the mouth, $D_{0}$ give 


$$
L=2980[Q \tan \alpha /(Z f)]^{0.5} \text {. }
$$

\subsubsection{Bathymetric framework}

By combining the above results for tidal current amplitude, $U$, and estuarine length, $L$, with the expression for the length of saline intrusion, $L_{\mathrm{I}}$, a 'Bathymetric Framework' for mixed estuaries was derived, shown in Fig. 3, enveloped by the conditions

1) $L_{\mathrm{I}} / L<1$,

2) $E_{\mathrm{X}} / L<1$ (where $E_{x}=2 U P / \pi$ is the tidal excursion length), and

3) the Simpson-Hunter criterion for vertical mixing, $D / U^{3}<50 \mathrm{~m}^{-2} \mathrm{~s}^{3}$ (Simpson and Hunter, 1974).

This framework for estuarine morphology in terms of the boundary conditions of tidal elevation amplitude, $Z$, and river flow, $Q$, indicates how tides and river flows determine estuarine size and shape.

\section{UK estuarine data set}

\subsection{Morphological data set}

Fig. 2 shows the locations and Table 1 summarises characteristics of the 96 estuaries of England and Wales included in this study. The morphological data for these estuaries of England and Wales were extracted from Burgess et al., 2002. Values were derived (Prandle et al., 2005 and 2006) for: depth at the mouth, $D_{0}$, mean width (at the mouth), $B$, mean lateral slope, $\tan \alpha$, tidal intrusion length, $L$, mean tidal amplitude (at the mouth), $Z$, mean river flow, $Q$.

\subsection{Assessment of theoretical relationship for UK estuaries}

Davidson and Buck (1997) encapsulated the varying estuarine types (summarised in Table 1) as follows:

- Rias are short, deep and steep-sided with small river flows.

- Coastal Plain estuaries are long and funnel-shaped with gently sloping triangular cross-sections providing extensive inter-tidal zones. 
- Bar-Built estuaries are short and shallow with small values of both river flow and tidal range.

Prandle (2003) noted that sandy estuaries tend to be short, while muddy estuaries tend to be long. In sedimentary terms, bar-built estuaries are located along coasts with plentiful supplies of marine sediments and, consequently, are close to present-day equilibrium. Coastal plain estuaries are continuing to infill following 'over-deepening' via post-glacial river flows, while rias are drowned river valleys (with related cross-sections) as a consequence of (relative) sea level rise. See Woodroffe (2002) for further descriptions of estuarine morphologies.

\subsubsection{Statistical fits between length, $L$, breadth, $B$, and depth, $D_{0}$}

Prandle (2006) determined optimum statistical fits between parameter pairs $x$ and $y$ in the form $x=A y^{N}$, with $A$ calculated from least squares fit over the range $-3<N<3$, where $N$ is the power of the variable $y$.

Table 2 shows relationships between: estuarine lengths, $L(\mathrm{~km})$, and breadths, $B(\mathrm{~m})$, and depths, $D_{0}(\mathrm{~m})$ with the correlation coefficients given in parentheses. The theoretical value is based upon the bed friction coefficient, $f$ of 0.0025 , and tidal elevation amplitude, $Z$ of $1.8 \mathrm{~m}$.

The fits between tidal length, $L$, and depth, $D_{0}$, show calculated power of depth, $D_{0}$, of 1.12 for coastal plain estuaries, and 1.15 for bar-built estuaries. These powers lie close to the theoretical value of 1.25 (Equation 4) as do the coefficients, $A$, of 1.95 and 1.92, for coastal plain and bar-built estuaries respectively, compared with the theoretical value of 1.83 . The power of depth, $D_{0}$, for ria estuaries of 1.10, is in reasonable agreement with the theoretical value of 1.25 , but the reduced value of the coefficient, $A$, of 0.99 , reflects the shorter lengths of these estuaries.

Prandle and Rahman (1980) introduced a parameter, $v$, to represent the dynamical influence of funnelling; this corresponds to

$$
v=\frac{n+1}{2-m}
$$

where $B(x)=B_{\mathrm{H}} x^{n}$ and $D(x)=D_{\mathrm{H}} x^{m} . B_{\mathrm{H}}$ and $D_{\mathrm{H}}$ represent breadth and depth at the head, with $x$ the axial distance from the head.

Taking the powers of tidal length, $L$ (in breadth, $B$, vs. length, $L$ ) to reflect $n$ and the inverse of the power of depth, $D_{0}$ (in length, $L$ vs. depth, $D_{0}$ ) to reflect $m$, the corresponding values of the 
funnelling factor, $v$, are shown in Table 2. Maximum tidal amplification occurs for $v \sim 1$, with considerable reduction of this peak for $v \sim 2$ (see Fig. 2.5 in Prandle, 2009). Thus, from the values for the funnelling factor, $v$, shown in Table 2, tidal elevations and currents are likely to be more spatially homogeneous in bar-built estuaries, reflecting conditions closer to equilibrium.

\subsubsection{Statistical fits between depth, $D_{0}$, length, $L$ and breadth, $B$ with river flow, $Q$}

Table 3 provides statistical fits between depth, $D_{0}$, tidal length, $L$ and breadth, $B$ with mean river flow, $Q$. As with the previous section, the correlation coefficients are given in parentheses. The theoretical values were calculated using a side slope, $\tan \alpha$ of 0.013 (the mean value calculated for all estuaries taken from Table 1). The fits between depth, $D_{0}$, and river flow, $Q$, show powers of $Q$ of 0.31 , for ria estuaries, and 0.38 for both coastal plain and bar-built estuaries. These latter values are all close to the theoretical value of 0.4 (from Equation 6). Likewise, the related values for the coefficient, $A$, are close to the theory except for ria estuaries, where the higher coefficient reflects their greater depths.

The fits between length, $L$, and river flow, $Q$, show an overall power of 0.68 for $Q$. This is somewhat larger than the theoretical value of 0.5 and (partly in consequence) the value of the coefficient, $A$, is smaller. The fit for coastal plain estuaries is closest to the theoretical values.

Overall we note statistically significant relationships (given by the $\mathrm{R}^{2}$ values in parentheses in Tables 2 and 3) between most of these parameters in all types of estuaries, indicating the tendency for morphologies to be confined within restricted parameter ranges. In addition, there is good agreement between typological classifications and statistical fits for the sizes and shapes of estuaries classified as either coastal plain or bar-built.

\section{Vulnerability indices}

Estuarine dynamical and mixing processes are encapsulated here by parameters representing mass flow, energetics and mixing rates. The tidal ebb and flood mass exchanges can be directly represented by the mean tidal current amplitude, $U$, which conveniently corresponds to the (predominant) semi-diurnal lunar tidal constituent, $\mathrm{M}_{2}$ in $\mathrm{UK}$ estuaries. Net tidal energy dissipation is proportional to $U^{3}$, and net upstream dissipation can be directly calculated from the synchronous estuary solutions described in Section 2.2. Prandle (2009) shows that the extent of vertical mixing is directly proportional to $U / U_{0}$, where $U_{0}$ is the velocity component of river flow (in the mixing 
zone). The extent of axial mixing is represented by the length of saline intrusion, $L_{\mathrm{I}}$, and the ratio of $L_{\mathrm{I}} / L$ (tidal length) is used below to characterise this process. The four primary indices described all have the advantage that impacts from changes in either sea level or river flow can be directly determined.

The 'Vulnerability Indices' for tidal currents, tidal energy dissipation and levels of vertical and axial mixing are illustrated in Figs. 5-8. They share common axes, namely depths, $D$, from 0 to $40 \mathrm{~m}$ and tidal elevation amplitude, $Z$, from 0 to $4 \mathrm{~m}$. The values of depth and tidal current amplitude ( $D$ and $Z$ ) are intended to represent values at the mouth of an estuary but, for Figs. 5 and 6, can also be applied to upstream regions (away from the extreme tidal limit).

Each diagram shows, in blue continuous contours, the salient parameter, i.e., tidal current amplitude, $U$, in Fig. 5; tidal energy dissipation in Fig. 6; vertical mixing, $U / U_{0}$, in Fig. 7, and salinity intrusion, $L_{\mathrm{I}} / L$, in Fig. 8. The contour values in Figs. 7 and 8 assume a value of $U_{0}=0.01 \mathrm{~m} \mathrm{~s}^{-1}$. The value of $U_{0}$ can be estimated from dividing the river flow, $Q$, by a representative value of the cross-sectional area within the intrusion region. Where $U_{0}$ differs significantly from $0.01 \mathrm{~m} \mathrm{~s}^{-1}$, i.e., falls outside of the range $0.005-0.02 \mathrm{~m} \mathrm{~s}^{-1}$ the blue contour values in these two figures must be multiplied by $0.01 / U_{0}$.

Each diagram has, superposed in red dashed contours, percentage impacts on the above indices resulting from an increase in sea level of $1 \mathrm{~m}$. In calculating these impacts for Figs. 5 and 6, it is assumed that river flow, $Q$, remains unchanged.

Away from the head of strongly tidal estuaries, changes in river flow have little impact on the results shown in Figs. 5 and 6. Impacts of changes in river flow, $\delta Q$, in river flow, $Q$, on the indices in Figs. 7 and 8 can be calculated directly by multiplying the (blue continuous) contour values by $Q /(Q+\delta Q)$.

Where a change in depth results in a change in tidal elevation amplitude (Prandle, 1989), resultant effects should be incorporated alongside those shown here. 


\subsection{Vulnerability index 1: mass flow}

For a synchronous estuary, the amplitude and phase of tidal currents $(U, \theta)$ can be calculated directly in terms of depth, $D$, tidal elevation amplitude, $Z$, and bed friction coefficient, $f$ (Equations 1-3) Currents in non-synchronous estuaries will generally be of similar magnitude. Concentrating on the principal semi-diurnal lunar tidal constituent, $\mathrm{M}_{2}$, the product of tidal current amplitude, $U$, and the cross-sectional area represents the average tidal mass exchange between the estuary and sea, which determines flushing rates for saline intrusion, sediments and dissolved contaminants. Thus any change in tidal current amplitude impacts on the magnitude of the entire flood and ebb exchanges. Fig. 5 indicates values of tidal current amplitude up to $1.5 \mathrm{~m} \mathrm{~s}^{-1}$.

As shown in Equation 1 current amplitude, $U$, can be represented by:

$U \propto Z^{1 / 2} D^{1 / 4} f^{-1 / 2}$ (in shallow water), and

$U \propto Z D^{-1 / 2}$ (in deep water, where depth, $D$, is greater than 10 times the tidal elevation amplitude, $Z$, or from Equation $1, F<<\omega)$.

The zero impact contour corresponds to conditions for maximum values of tidal current amplitude, which occur when $D \sim 5+10 Z(\mathrm{~m})$. In deeper water little sensitivity is shown. In depths less than $10 \mathrm{~m}$, increases in tidal current amplitude up to $5 \%$ occur in the estuaries shown.

\subsection{Vulnerability index 2: energetics}

Tidal energy dissipation by bed friction occurs at the rate $\rho f U^{3}$ per square metre ( $\rho$ is the density of water). At any estuarine section, the summation of all such upstream dissipation, DISS, is approximated by (Taylor, 1920)

$$
D I S S=0.5 \rho g D Z U \cos \theta
$$

where $\theta$ is the phase difference between tidal elevation and current amplitudes. From Equation 2, $\tan \theta=-F / \omega$, where $F$ is the linearised friction coefficient and $\omega$, tidal frequency.

Fig. 6 shows values of DISS as a function of depth, $D$, and tidal elevation amplitude, $Z$, alongside impacts of a rise in mean sea level of $1 \mathrm{~m}$. 
Values of DISS range from less than $10 \mathrm{~kW}$ per metre breadth in shallow, micro-tidal estuaries, to upwards of $1000 \mathrm{MW}$ per km breadth in the deepest macro-tidal conditions. The impacts of the sea level rise range from over $5 \%$ in the deepest estuaries to upwards of $50 \%$ in depths less than $4 \mathrm{~m}$.

These impacts on net upstream dissipation are indicative of how sea bed conditions and related habitats may change. Bed stress induced by tidal currents is proportional to $U^{2}$, hence related impacts will lie mid-way between those shown in Figs. 5 and 6.

\subsection{Vulnerability index 3: vertical mixing}

Prandle (2009) showed that the ratio, given by the modified Stratification Number, $S_{T}{ }^{\prime}$ (Ippen,1966), of the available tidal energy (effective in mixing) to that required to mix river and sea water within the saline intrusion length can be approximated by:

$$
S_{T}{ }^{\prime} \sim 6.8 \times 10^{-5}\left(U / U_{0}\right)^{2}
$$

Thus a balance, $S_{T}{ }^{\prime}=1$, occurs when $U_{0} \sim 0.01 U$. Prandle (2009) also showed that the Richardson Number, $R i$, representing the balance between buoyancy (stabilising) and turbulent (mixing) forces, can be approximated by

$$
R i=100\left(U_{0} / U\right)^{2}
$$

It has been shown that mixing can only occur when $R i<0.25$, i.e., when $U_{0}<0.05 U$. Hence, estuaries will tend to form stratified saline wedges for $U_{0}>0.05 U$ and will be fully mixed for $U_{0}<0.01 U$.

Fig. 7 shows values of $U / U_{0}$ as a function of depth, $D$ and tidal elevation amplitude, $Z$ for the bed friction coefficient, $f=0.0025$ and river flow velocity, $U_{0}=0.01 \mathrm{~m} \mathrm{~s}^{-1}$. The two demarcation parameters described above correspond closely to both observed and theoretical limits.

The impacts of a rise in mean sea level of $1 \mathrm{~m}$ on $U / U_{0}$, shown in Fig. 7, vary from an increase of less than $5 \%$ in deep water to in excess of $25 \%$ in shallow water. The component changes in tidal 
current amplitude, $U$, shown in Fig. 5, are much smaller, emphasising how the greater effect here is from the reduction in river flow velocity, $U_{0}$, as a result of the increased cross-sectional area.

These results must be adjusted for prevailing mean values of river flow velocity, which were calculated from

$$
U_{0}=Q \tan \alpha / D^{2}
$$

where $\tan \alpha$ is the side-slope gradient. Mean values shown in Table 1 are as follows: all estuaries $0.5 \mathrm{~cm} \mathrm{~s}^{-1}$; Rias $-0.04 \mathrm{~cm} \mathrm{~s}^{-1}$; Coastal Plain $-0.3 \mathrm{~cm} \mathrm{~s}^{-1}$; Bar-Built $-1.0 \mathrm{~cm} \mathrm{~s}^{-1}$.

Prandle (2004a) showed that values of river flow velocity, $U_{0}$, derived both from observations worldwide and numerical model calculations are generally in the range $0.2-1.5 \mathrm{~cm} \mathrm{~s}^{-1}$. The much lower values for ria estuaries reflect their peculiar morphological development. It was shown in Equation 7 that $U_{0} \sim D_{0}^{0.5} / 333 \mathrm{~m} \mathrm{~s}^{-1}$, this is equivalent to $0.006 \mathrm{~m} \mathrm{~s}^{-1}$ for $D_{0}=4 \mathrm{~m}$, and $0.02 \mathrm{~m} \mathrm{~s}^{-1}$ for $D_{0}=40 \mathrm{~m}$.

To maintain values of river flow velocity, $U_{0}$, within the range indicated above following sea level rise, estuaries must either accrete to maintain values of depth, $D_{0}$, or decrease in breadth, $B$, or some combination of both.

Impacts from changes in river flows can be calculated directly from the associated changes in $U_{0}$.

\subsection{Vulnerability index 4: salinity intrusion}

In addition to changes in mixing and stratification levels described in Section 4.3, changes in mean sea level will also impact on the length of saline intrusion, $L_{\mathrm{I}}$. Fig. 8 shows the ratio $\left(L_{\mathrm{I}} / L\right)$ of salinity intrusion length $L_{\mathrm{I}}$ to tidal length, $L$ as a function of depth, $D_{0}$ and tidal elevation amplitude, $Z$ for river flow velocity, $U_{0}=0.01 \mathrm{~m} \mathrm{~s}^{-1}$.

The contour $L_{\mathrm{I}} / L=1$, reflects the limit for mixing to be contained within an estuary.

The impacts of a rise in mean sea level of $1 \mathrm{~m}$ range from an increase in intrusion length of not more than $7 \%$ in deep water to in excess of $25 \%$ in depths shallower than $10 \mathrm{~m}$. 
Changes in river flow, $Q$, impact directly, but inversely on $L_{\mathrm{I}} / L$.

\subsection{Changes in morphology}

Prandle (2006) indicated the scale of likely changes to depth, length and breadth $\left(D_{0}, L\right.$ and $\left.B\right)$ for a rise in mean sea level of $0.5 \mathrm{~m}$ and changes in river flow, $Q$, of $\pm 25 \%$. These changes were based on estimates of 'precautionary' differences in mean sea level by 2100 provided by technical summaries from Defra/Environment Agency (2003, 2004). Using the formulae shown in Section 2.2 for synchronous estuaries, inserting these changes in river flow, $Q$, and the resulting changes in depth, $\delta D$, we can estimate the changes in length, $\delta L$. Likewise the changes in breadth, $\delta B$, associated with the changes in depth, $\delta D$ can be estimated by assuming the side-slope gradients, $\tan \alpha$, are unchanged. Table 4 provides quantitative indications of the resultant changes for the estuarine data sets shown in Fig. 2.

Overall we anticipate, due to the $25 \%$ variation in river flow, changes in:

- estuarine lengths of the order of $0.5-5 \mathrm{~km}$ and

- breadths of the order 50-250 m.

Corresponding changes due a rise in mean sea level of $50 \mathrm{~cm}$ are: increases in tidal length of the order $1-2.5 \mathrm{~km}$ and breadths of $70-100 \mathrm{~m}$.

\section{Conclusions - identifying estuaries vulnerable to Global Climate Change}

Recently developed theories, describing estuarine tidal dynamics and associated links with morphology have been shown to be broadly accurate in applications to 96 estuaries in England and Wales. These theories were based on the assumption of a synchronous estuary and have been shown to be broadly applicable in macro- and meso-tidal conditions. The theories are used to estimate likely developments resulting from projected changes in both mean sea level and river flows linked to future global climate change scenarios.

Four 'Vulnerability Indices' were derived as functions of tidal elevation amplitude, $Z$, and depth at the mouth, $D$. 


\subsection{Vulnerability index 1: mass flow (Fig. 5)}

The mass flow index is represented by the mean tidal current amplitude $U$ of the predominant semidiurnal lunar tidal constituent, $\mathrm{M}_{2}$. Values of $U$ increase with depth up to a maximum at approximately $D \sim 5+10 Z$, where $Z$ is the tidal elevation amplitude (m), and then remain nearly constant in deeper water. Impacts from a rise in mean sea level of $1 \mathrm{~m}$ have negligible effects on $U$ in these deeper waters. By contrast, in the shallowest depths of approximately $5 \mathrm{~m}$, a $1 \mathrm{~m}$ rise in mean sea level increases the tidal current amplitude, $U$, by $5 \%$.

Away from the head, changes in river flow have little effect on tidal current amplitude.

\subsection{Vulnerability index 2: energetics (Fig. 6)}

Since the rate of tidal dissipation is proportional to the cube of the tidal current amplitude, $U^{3}$, the small changes in $U$ described for 'Vulnerability Index 1' are multiplied by a factor of approximately three.

Consequently a rise in sea level of $1 \mathrm{~m}$ results in net tidal dissipation increases in excess of $25 \%$ in depths less than $5 \mathrm{~m}$. This is likely to lead to changes in surface sediment distributions with attendant impacts on habitats.

\subsection{Vulnerability index 3: vertical mixing (Fig. 7)}

The extent of vertical mixing can be shown to be directly proportional to the ratio between the tidal current amplitude and the river flow velocity $\left(U / U_{0}\right)$ :

- complete vertical mixing occurs for values of $U>100 U_{0}$

- $\quad$ stratification occurs for $U<20 U_{0}$.

Fig. 7 confirms earlier studies, Prandle (2004a), which show that complete mixing is likely in macro-tidal estuaries, while persistent stratification will generally be confined to micro-tidal estuaries. 
Impacts of a rise in mean sea level of $1 \mathrm{~m}$ on $U / U_{0}$ (assuming no change in river flow, $Q$ ) ranges from an increase of less than 5\% in deep water to in excess of $25 \%$ in depths of less than $10 \mathrm{~m}$.

Impacts of changes in river flow, $\delta Q$, involve multiplying $U / U_{0}$ by $Q /(Q+\delta Q)$.

These results suggest that:

- in depths of greater than $10 \mathrm{~m}$, only small impacts on levels of vertical mixing will occur

- in shallower water $(<10 \mathrm{~m})$, significant differences are likely, exacerbated in micro and mesotidal estuaries by increased intervals of stratification.

\subsection{Vulnerability index 4: salinity intrusion (Fig. 8)}

In addition to changes in vertical mixing described for 'Vulnerability Index 3', changes in mean sea level and river flow also impact on the length of saline intrusion, $L_{\mathrm{I}}$.

A rise in mean sea level of $1 \mathrm{~m}$ increases the ratio of salinity intrusion to estuarine tidal length, $L_{\mathrm{I}} / L$ by (Equation 5$)$ :

- as little as $7 \%$ in the deepest water and

- in excess of $25 \%$ in depths shallower than $10 \mathrm{~m}$.

Changes in river flow, $\delta Q$, involve multiplying this ratio $\left(L_{\mathrm{I}} / L\right)$ by $Q /(Q+\delta Q)$.

Thus both sea level rise and decreases in river flow could result in significant increases in the extent of saline intrusion with this effect substantially enhanced in shallow water.

\subsection{Summary}

Overall, a rise in mean sea level of $1 \mathrm{~m}$ is likely to result in:

- major impacts on the shallowest $10 \%$ of UK estuaries, $>5 \%$ increase in currents, and $>20 \%$ increase in tidal dissipation, potentially large changes in both the vertical stratification index and the length of saline intrusion 
- $\quad$ significant effects on half of UK estuaries, $\sim 5 \%$ increase in currents, and $\sim 20 \%$ increase in tidal dissipation, the vertical stratification index and the length of saline intrusion

- smaller effects on a further half of UK estuaries, $\sim 1 \%$ increase in currents, and $\sim 10 \%$ increase in tidal dissipation, the vertical stratification index and the length of saline intrusion

- little effect on the largest $10 \%$ of UK estuaries.

Impacts of changes in river flow, $\delta Q$, involve multiplying the 'stratification parameter', $\left(U / U_{0}\right)^{2}$ and similarly for the length of saline intrusion $\left(\sim 1 / U_{0}\right)$ accordingly. Hence we expect an inverse linear response for intrusion lengths and an inverse squared response for stratification. However, sensitivity to the latter may be small in those well-mixed estuaries removed from the stratification condition shown in Fig. 7.

Morphological impacts likely from changes in river flows were shown by Prandle (2006) and summarised in Table 4 . The morphological adjustment to a $25 \%$ increase in river flows corresponds (approximately) to a $10 \%$ increase in depths and a $12.5 \%$ increase in lengths. The above results for dynamical and mixing processes in estuaries need to be considered alongside these likely associated changes in morphology.

\section{References}

Brown, J.M., and Davies, A.G., 2007. Flood/ebb tidal dominance in an estuary: sediment transport and morphology. River, Coastal and Estuarine Morphodynamics: RCEM 2007, two volume set. Proceedings of the 5th IAHR Symposium on River, Coastal and Estuarine Morphodynamics, Enschede, NL. 779-787.

Burgess, K.A., Balson, P., Dyer, K.R., Orford, J. and Townend, I.H., 2002. Futurecoast: The integration of knowledge to assess future coastal evolution at a national scale. In: 28th International Conference on Coastal Engineering. American Society of Civil Engineering, Cardiff, UK, Vol. 3. 3221-3233.

Davidson, N.C., and Buck, A.L., 1997. An inventory of UK estuaries. In: Introduction And Methodology, Vol. 1 (of 7). Joint Nature Conservation Committee, Peterborough, UK, 46pp. ISBN 1873701365

Defra/Environment Agency, 2003. Climate change scenarios UKCIP02: Implementation for flood and coastal defence. R\&D Technical Summary. W5B-029/TS

Defra/Environment Agency, 2004. Impact of climate change on flood flows in river catchments. Technical Summary. W5-032/TS 
Dyer, K.R., 1997. Estuaries: a physical introduction. 2nd Ed., John Wiley, Hoboken, NJ, USA, 195pp. ISBN 9780471974710

IPCC, 2001. Climate Change 2001: Synthesis Report. A contribution of Working Groups I, II, and III to the Third Assessment Report of The Intergovernmental Panel On Climate Change [Watson, R.T. and The Core Writing Team (Eds.)]. Cambridge University Press, Cambridge, United Kingdom, and New York, NY, USA, 398pp. ISBN 9780521015073

IPCC, 2014. Climate Change 2014: Synthesis Report. A contribution of Working Groups I, II, and III to the Fifth Assessment Report of The Intergovernmental Panel On Climate Change [Core Writing Team, Pachauri, R.K. and Meyer, L.A. (Eds.)]. IPCC, Geneva, Switzerland, 151pp. ISBN 9789291691432

Available online at: www.ipcc.ch/report/ar5/syr (retrieved March 2015).

Ippen, A.T. (editor), 1966. Estuary and coastline hydrodynamics. McGraw-Hill, New York, NY, USA, 744pp. ISBN 9780070320154

Prandle, D., 1989. The impact of mean sea level change on estuarine dynamics. C-7-C-14 in: Hydraulics and the environment. Proceedings of the International Association for Hydraulic Research, 23rd Congress, 21-25 August 1989, Ottawa, Canada. Technical Session C: Marine Hydraulics. Ottawa: National Research Council Canada. (5 vols.)

Prandle, D., 2003. Relationships between tidal dynamics and bathymetry in strongly convergent estuaries, Journal of Physical Oceanography, 33(12), 2738-2750. doi:10.1175/15200485(2003)033<2738:RBTDAB > 2.0.CO;2

Prandle, D., 2004a. How tides and river flow determine estuarine bathymetry. Progress in Oceanography. 61, 1-26. doi:10.1016/j.pocean.2004.03.001

Prandle, D., 2004b. Saline intrusion in partially mixed estuaries. Estuarine Coastal \& Shelf Sciences, 59, 385-397. doi:10.1016/j.ecss.2003.10.001

Prandle, D., 2006. Dynamical controls on estuarine bathymetry: Assessment against UK database. Estuarine Coastal \& Shelf Sciences, 68(1-2), 282-288. doi:10.1016/j.ecss.2006.02.009

Prandle, D., 2009. Estuaries: Dynamics, mixing, sedimentation and morphology. Cambridge University Press, Cambridge, UK, 235pp. ISBN 9780521297813

Prandle, D., Lane, A. and Manning, A.J., 2005. Estuaries are not so unique. Geophysical Research Letters, 32(23): 5pp. doi:10.1029/2005GL024797

Prandle, D., Lane, A. and Manning, A.J., 2006. New typologies for estuarine morphology. Geomorphology, 81(3-4), 309-315. doi:10.1016/j.geomorph.2006.04.017

Prandle, D. and Rahman, M. 1980. Tidal response in estuaries. Journal of Physical Oceanography, 10(10), 1552-1573. doi:10.1175/1520-0485(1980)010<1552:TRIE >2.0.CO;2

van Rijn, L.C., 2011. Analytical and numerical analysis of tides and salinities in estuaries; part I: Tidal wave propagation in convergent estuaries, Ocean Dynamics, 61(11), 1719-1741. doi:10.1007/s10236-011-0453-0 
Simpson, J.H. and Hunter, J.R., 1974. Fronts in the Irish Sea. Nature, 250, 404-406. doi:10.1038/250404a0

Taylor, G.I., 1920. Tidal friction in the Irish Sea. Philosophical Transactions of the Royal Society of London, A220, 239-264. doi:10.1098/rsta.1920.0001

Wang, B., Fringer, O.B., Giddings, S.N. and Fong, D.A., 2009. High-resolution simulations of a macrotidal estuary using SUNTANS. Ocean Modelling, 26(1-2), 60-85.

doi:10.1016/j.ocemod.2008.08.006

Woodroffe, C.D., 2002 Coasts: Form, process and evolution. Cambridge University Press, UK, 623pp. ISBN 9780521011839 
Table 1 Mean values of tidal elevation amplitude, $Z$, river flow, $Q$, depth, $D_{0}$, length, $L$, breadth, $B$ and lateral slope, $\tan \alpha$, for three estuarine types (after Prandle, 2006).

\begin{tabular}{lllllll}
\hline & $\begin{array}{l}\text { Tidal elevation } \\
\text { amplitude, } \\
Z(\mathrm{~m})\end{array}$ & $\begin{array}{l}\text { River } \\
\text { flow, } \\
Q\left(\mathrm{~m}^{3} \mathrm{~s}^{-1}\right)\end{array}$ & $\begin{array}{l}\text { Depth, } \\
D_{0}(\mathrm{~m})\end{array}$ & $\begin{array}{l}\text { Tidal } \\
\text { length, } \\
L(\mathrm{~km})\end{array}$ & $\begin{array}{l}\text { Breadth, } \\
B(\mathrm{~m})\end{array}$ & $\begin{array}{l}\text { Lateral } \\
\text { (side) slope } \\
\tan \alpha\end{array}$ \\
\hline All - mean & 1.8 & 14.9 & 6.5 & 20 & 970 & 0.013 \\
All - minimum $^{\dagger}$ & 1.2 & 0.2 & 2.5 & 5 & 130 & 0.004 \\
All - maximum $^{\dagger}$ & 2.6 & 35.9 & 17.3 & 41 & 3800 & 0.129 \\
Ria & 1.7 & 6.3 & 9.3 & 12 & 490 & 0.037 \\
Coastal plain & 2.0 & 17.9 & 8.1 & 33 & 1500 & 0.011 \\
Bar-built & 1.6 & 9.5 & 3.6 & 9 & 510 & 0.014 \\
\hline
\end{tabular}

$\dagger$ 10th percentile

$\$ 90$ th percentile

Table 2 Statistical fit between length, $L$, breadth, $B$ and depth, $D_{0}$ with calculated funnelling factor, $v$.

\begin{tabular}{lllll}
\hline Type & $L \sim A D_{0}{ }^{N}$ & $B \sim A D_{0}{ }^{N}$ & $B \sim A L^{N}$ & $v=\frac{n+1}{2-m}$ \\
\hline All & $1.28 D_{0}{ }^{1.24}(0.69)^{\dagger}$ & $38 D_{0}{ }^{1.38}(0.59)$ & $15.7 L^{1.20}(0.69)$ & 1.85 \\
Ria & $0.99 D_{0}{ }^{1.10}(0.89)$ & $25 D_{0}{ }^{1.33}(0.95)$ & $51.4 L^{0.89}(0.94)$ & 1.72 \\
Coastal plain & $1.95 D_{0}{ }^{1.12}(0.69)$ & $93 D_{0}{ }^{1.10}(0.64)$ & $7.8 L^{1.30}(0.64)$ & 2.07 \\
Bar-built & $1.92 D_{0}{ }^{1.15}(0.66)$ & $25 D_{0}{ }^{1.99}(0.66)$ & $9.4 L^{1.24}(0.71)$ & 2.25 \\
Theory & $1.83 D_{0}{ }^{1.25}$ & & & \\
\hline
\end{tabular}

${ }^{\dagger}$ Figures in parentheses represent the correlation coefficients $\left(\mathrm{R}^{2}\right)$

$\$$ Theory for bed friction coefficient, $f=0.0025$ and tidal elevation amplitude, $Z=1.8 \mathrm{~m}$

Table 3 Statistical fits between depth, $D_{0}$, length, $L$ and breadth, $B$ vs. river flow, $Q$.

\begin{tabular}{lllr}
\hline Type & $D_{0} \sim A Q^{N}$ & $L \sim A Q^{N}$ & $B \sim A Q^{N}$ \\
\hline All & $3.3 Q^{0.47}(0.55)^{\dagger}$ & $3.0 Q^{0.68}(0.64)$ & $98 Q^{0.86}(0.75)$ \\
Ria & $5.1 Q^{0.31}(0.74)$ & $3.1 Q^{0.74}(0.93)$ & $41 Q^{1.05}(0.80)$ \\
Coastal plain & $3.0 Q^{0.38}(0.67)$ & $6.7 Q^{0.64}(0.89)$ & $106 Q^{0.85}(0.71)$ \\
Bar-built & $2.4 Q^{0.38}(0.72)$ & $9.2 Q^{1.37}(0.21)$ & $11 Q^{1.37}(0.50)$ \\
Theory & $2.3 Q^{0.4}$ & $5.8 Q^{0.5}$ & \\
\hline
\end{tabular}

${ }^{\dagger}$ Figures in parentheses represent the correlation coefficients $\left(\mathrm{R}^{2}\right)$

$\$$ Theory for bed friction coefficient, $f=0.0025$ and tidal elevation amplitude, $Z=1.8 \mathrm{~m}$ 
Table 4 Changes in depth, $\delta D_{Q}$, length, $\delta L_{Q}$ and breadth, $\delta B$ due to a $25 \%$ change in river flow, subscript ' $Q$ ', and a $0.5 \mathrm{~m}$ increase in mean sea level, subscript ' $m$ sl' (after Prandle, (2006).

\begin{tabular}{lrlllllrl}
\hline Type & $D_{0}(\mathrm{~m})$ & $\begin{array}{l}\delta D_{Q} \\
+/-\end{array}$ & $L(\mathrm{~km})$ & $\begin{array}{l}\delta L_{Q} \\
+/-\end{array}$ & $\begin{array}{l}\delta L_{\mathrm{msl}} \\
+\end{array}$ & $B(\mathrm{~m})$ & $\begin{array}{r}\delta B_{Q} \\
+/-\end{array}$ & $\begin{array}{l}\delta B_{\mathrm{msl}} \\
+\end{array}$ \\
\hline All minimum & 2.5 & 0.25 & 5 & 0.62 & 1.28 & 130 & 38 & \\
All mean & 6.5 & 0.65 & 20 & 2.50 & 1.94 & 970 & 100 & 77 \\
All maximum & 17.3 & 1.73 & 41 & 5.12 & 1.49 & 3800 & 266 & \\
Coastal plain & 8.1 & 0.81 & 33 & 4.12 & 2.57 & 1500 & 147 & 91 \\
\hline
\end{tabular}




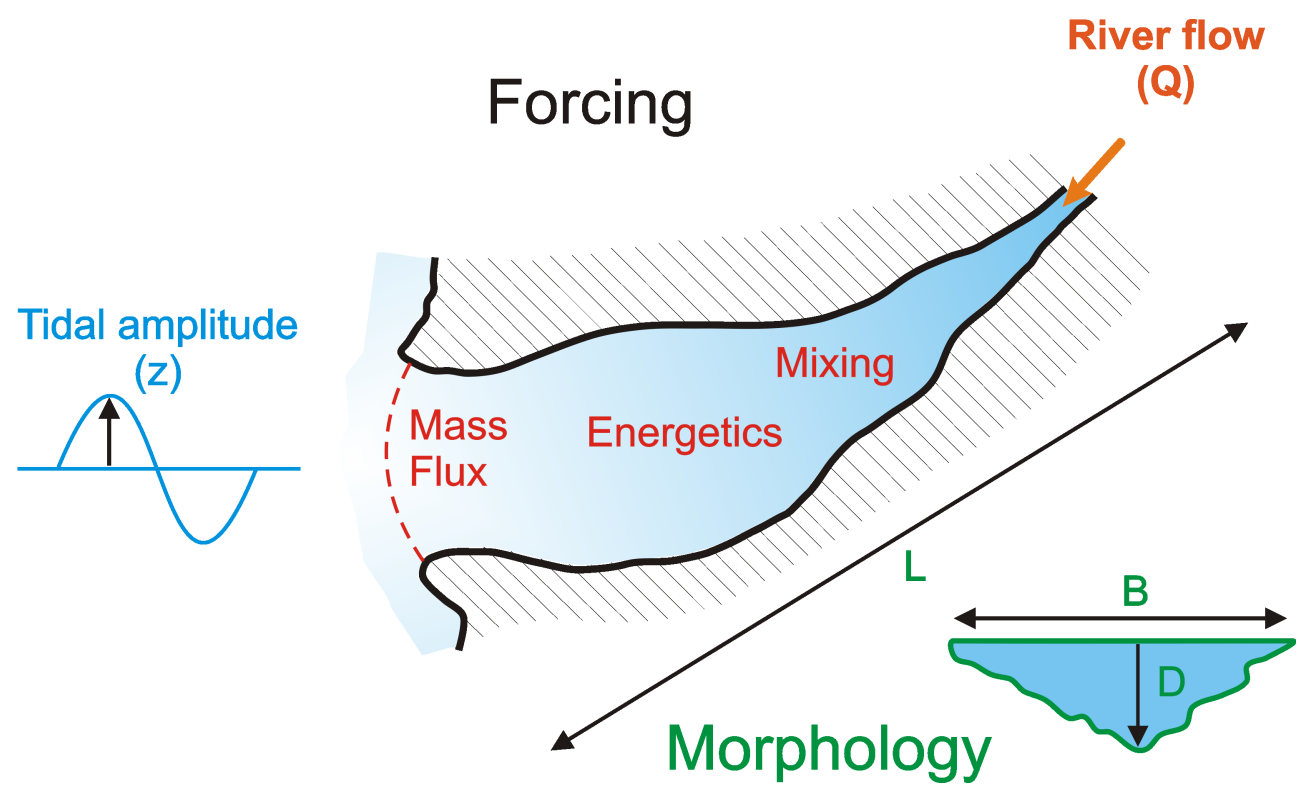

Fig. 1 Forcing, internal processes and morphology in estuaries.

$$
\begin{array}{ll}
B & \text { - channel breadth } \\
D & \text { - depth } \\
D_{0} & \text { - depth at mouth } \\
L & \text { - estuarine tidal length } \\
L_{\mathrm{I}} & \text { - salinity intrusion length } \\
Q & \text { - river flow } \\
Z & \text { - tidal elevation amplitude }
\end{array}
$$




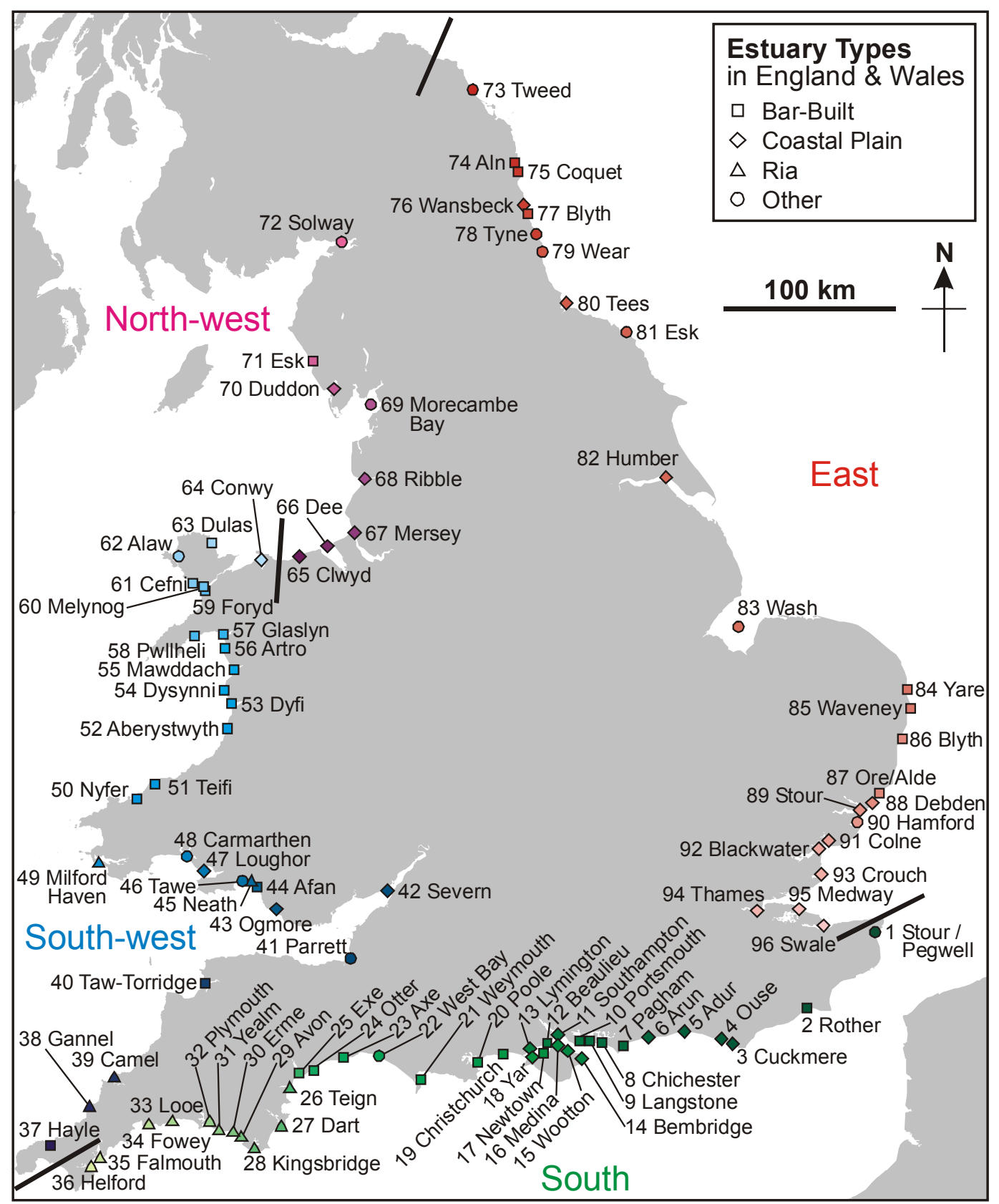

Fig. 2 Estuaries of England and Wales morphological types (Burgess et al., 2002), after Davidson and Buck (1997). 


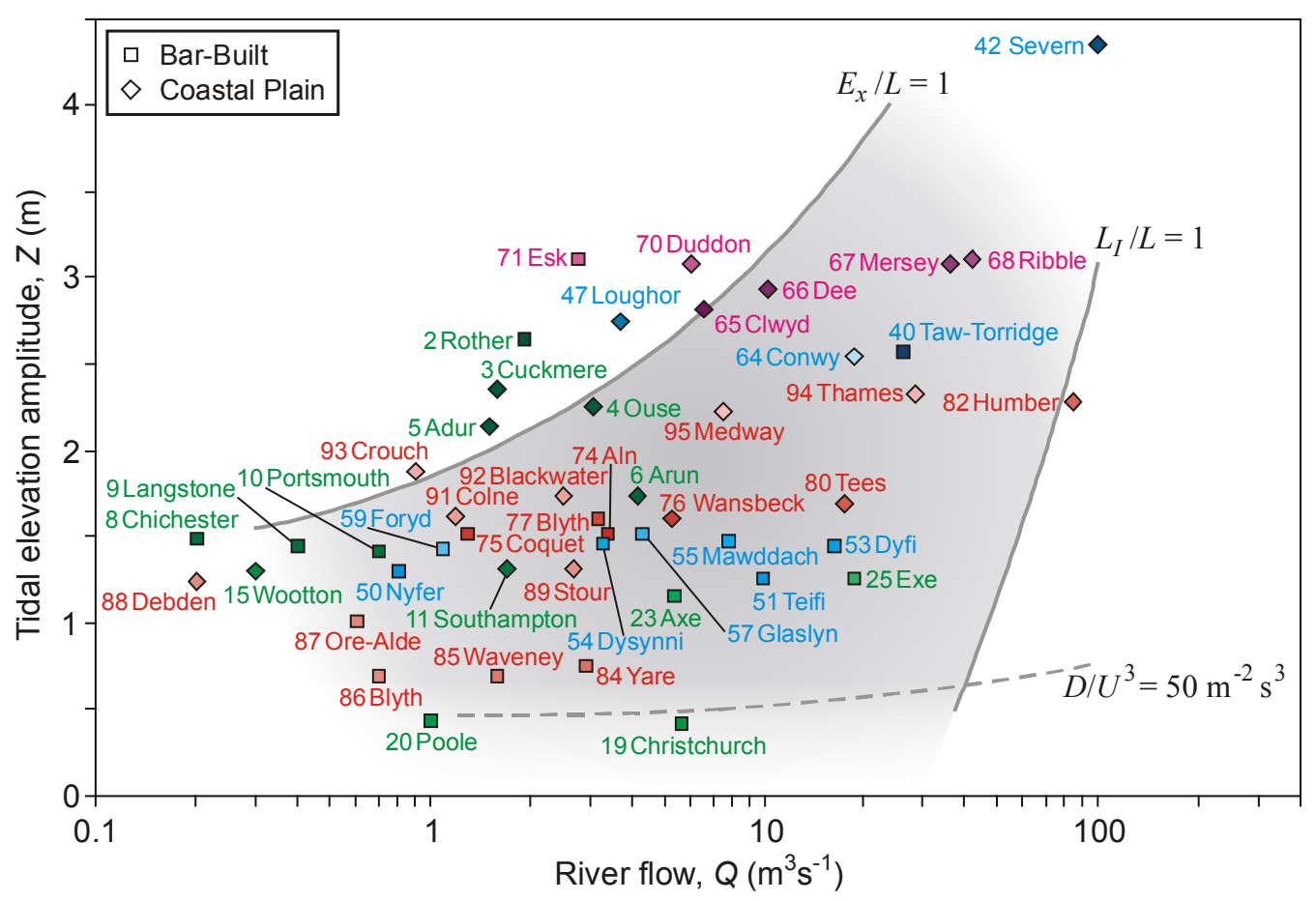

Fig. 3 Estuarine bathymetric zone after Prandle et al. (2005).

Vertical axis corresponds to tidal elevation amplitude, $Z$, bounded by $E_{\mathrm{x}}<L, L_{\mathrm{I}}<\mathrm{L}$ and $D / U^{3}<50 \mathrm{~m}^{-2} \mathrm{~s}^{3}$

green - south coast, blue - south-west coast \& Wales, red - east coast, magenta - north-west coast

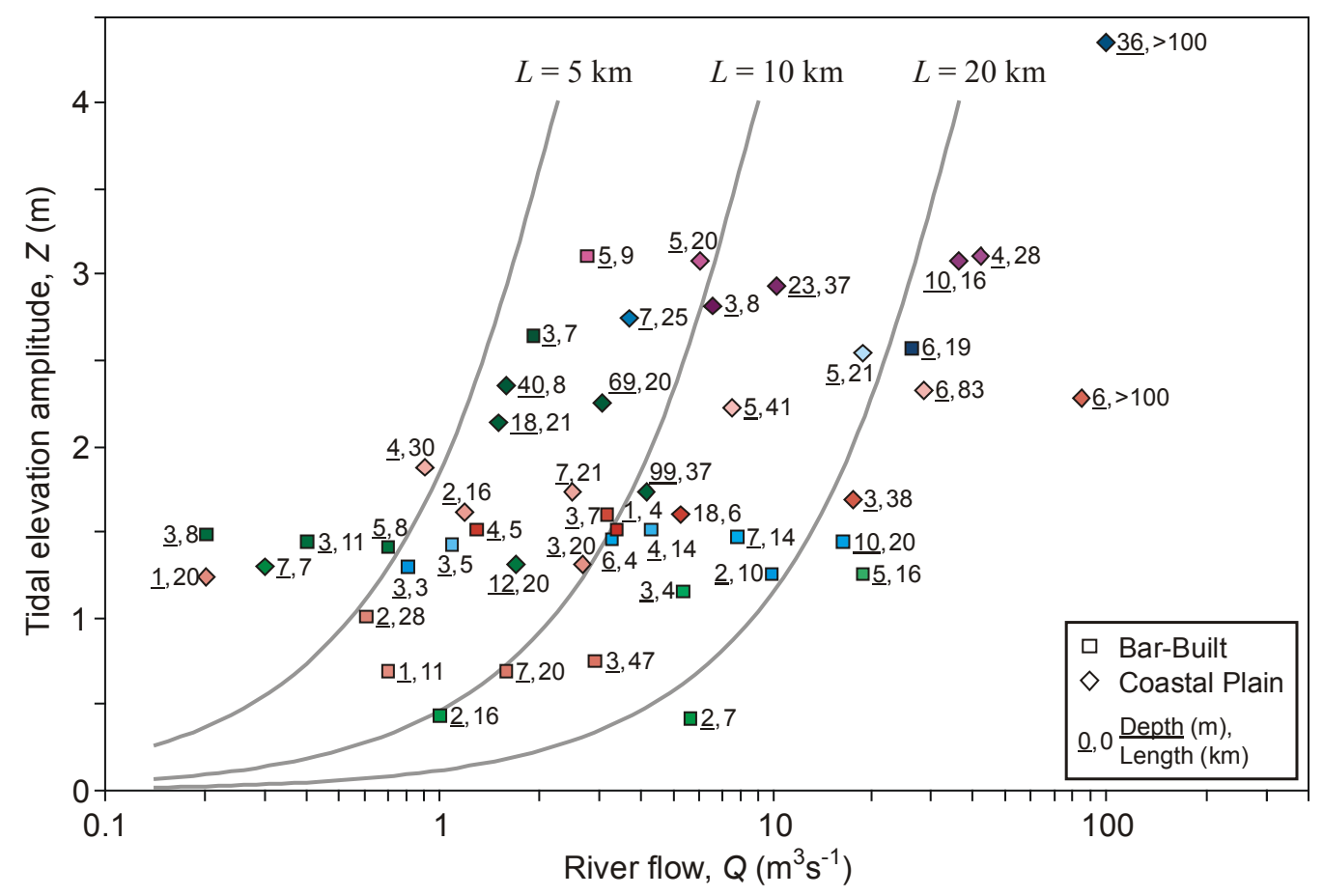

Fig. 4 Theoretical estuarine lengths, $L$, and depths at the mouth, $D_{0}$ (Equation 8 for side slope, $\tan \alpha=0.013)$, Prandle et al. (2005).

Observed values: (left, underlined) depth in metres, (right) length in km green - south coast, blue - south-west coast \& Wales, red - east coast, magenta - north-west coast 


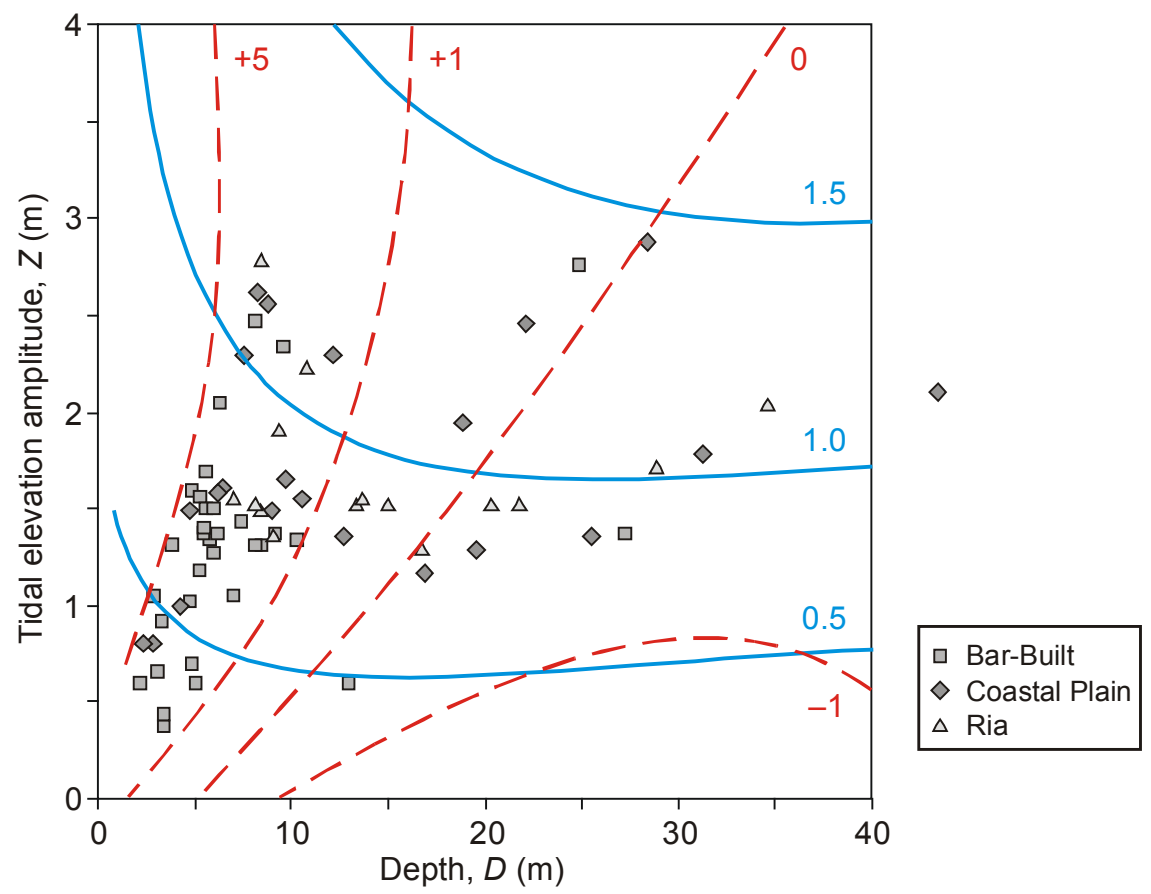

Fig. 5 Tidal current amplitude, $U$, as a function of depth, $D$, and tidal elevation amplitude, $Z$. Notes: based on bed friction coefficient, $f=0.0025$ continuous blue contours - tidal current amplitude, $U$, in $\mathrm{m} \mathrm{s}^{-1}$ dashed red contours - percentage increase in tidal current amplitude, $U$ for a rise in mean sea level of $1 \mathrm{~m}$

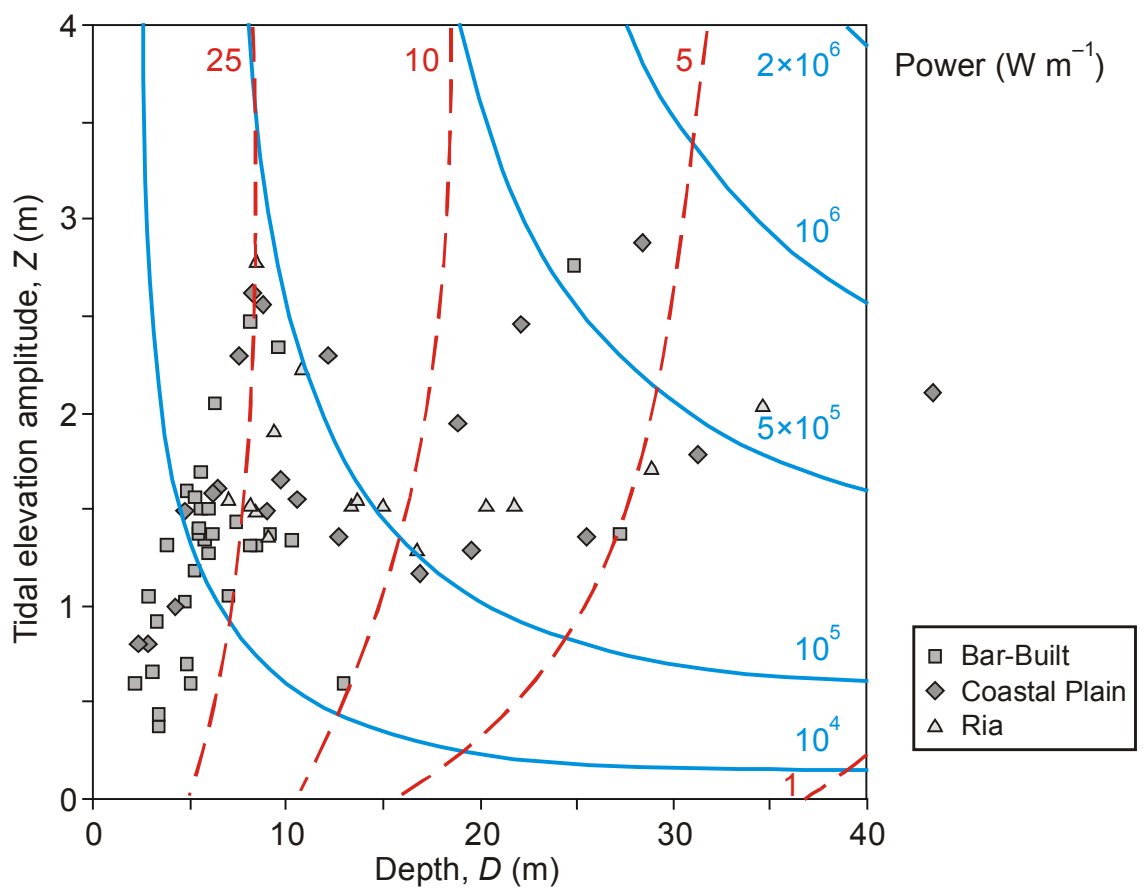

Fig. 6 Upstream tidal power dissipation per metre breadth $(0.5 \rho g D Z U \cos \theta)$.

Notes: continuous blue contours - dissipation per metre width in $\mathrm{W} \mathrm{m}^{-1}$ dashed red contours - percent increase in dissipation for rise in mean sea level of $1 \mathrm{~m}$ 


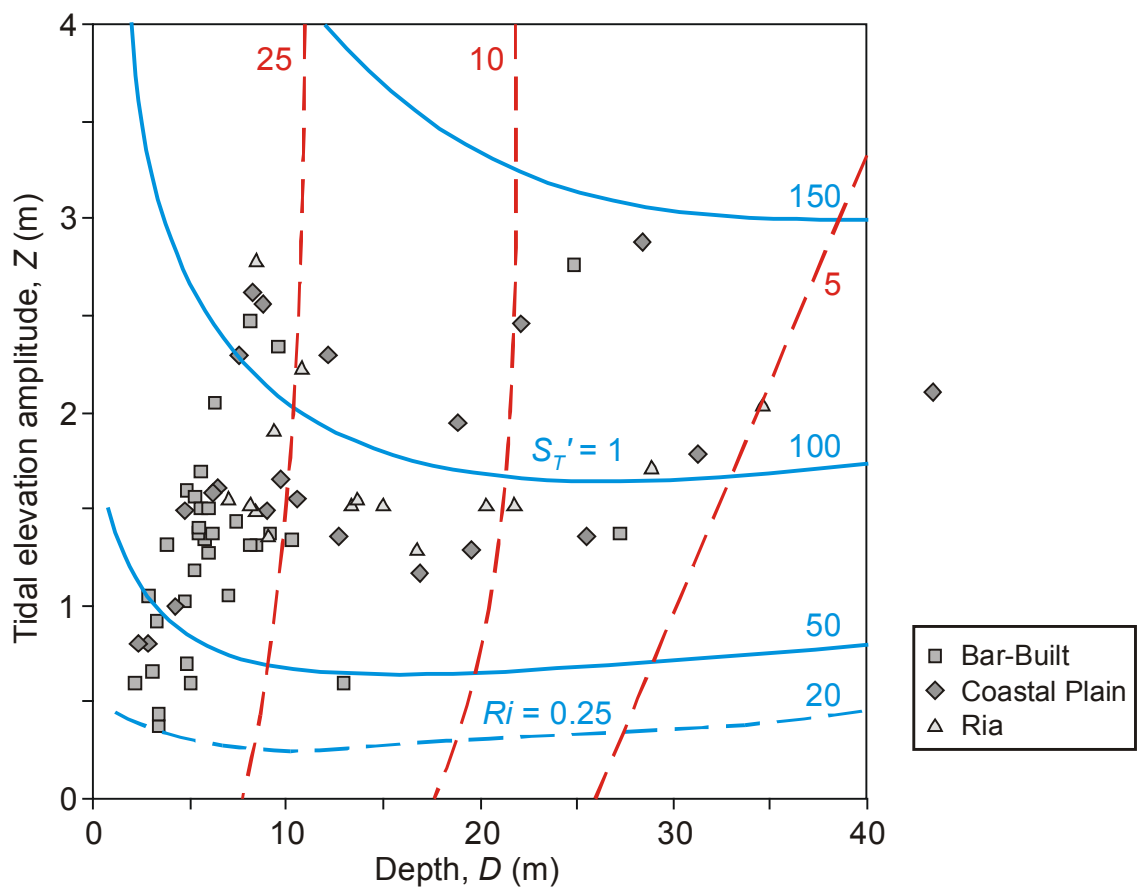

Fig. 7 Ratio of tidal to river flow, $U / U_{0}$ as a function of depth, $\boldsymbol{D}$ and tidal elevation amplitude, $Z$.

Notes: continuous blue contours - ratio of $U / U_{0}$, for $U_{0}$ of $0.01 \mathrm{~m} \mathrm{~s}^{-1}$

dashed red contours - percentage increase in $U / U_{0}$ for rise in mean sea level of $1 \mathrm{~m}$ (assuming constant river flow, $Q$ )

Stratification Number, $S_{T}{ }^{\prime}=1$, corresponds to $U / U_{0}=100$

critical Richardson Number, $R i=0.25$ corresponds to $U / U_{0}=20$

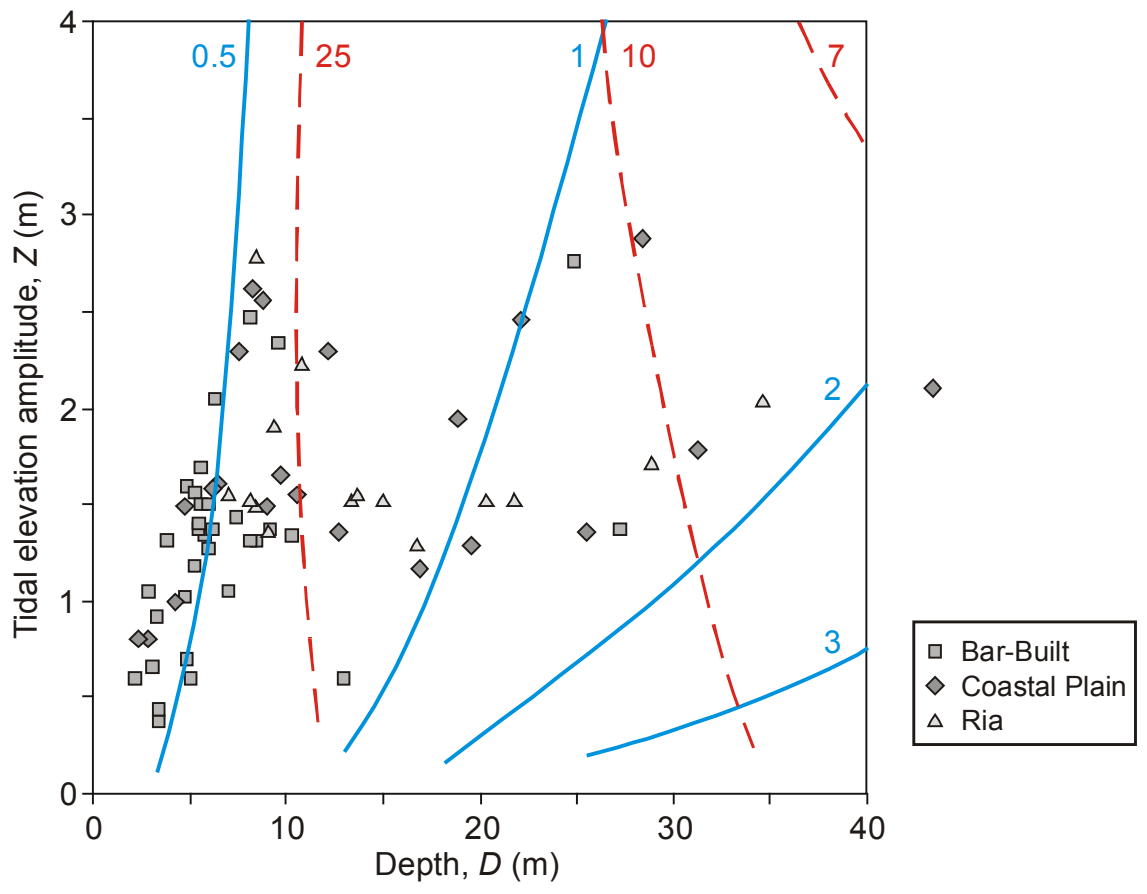

Fig. 8 Ratio of saline intrusion length, $L_{\mathrm{I}}$ to estuarine length, $L$ as a function of depth, $D_{0}$ and tidal elevation amplitude, $Z$.

Notes: continuous blue contours - ratio of $L_{\mathrm{I}} / L$ for $U_{0}$ of $0.01 \mathrm{~m} \mathrm{~s}^{-1}$

dashed red contours - percentage increase in $L_{\mathrm{I}} / L$ for rise in mean sea level of $1 \mathrm{~m}$ (assuming constant river flow, $Q$ ) 